\title{
STABILITY RESULT OF LAMINATED BEAM WITH INTERNAL DISTRIBUTED DELAY
}

\section{Kassimu Mpungu* And TiJani A. Apalara}

\begin{abstract}
In this paper, we consider a laminated Timoshenko beam system with frictional damping and an internal distributed delay feedback on the effective rotational angle. Under appropriate assumptions on the weight of the delay term and wave speeds of the first two equations of the system, we prove that the dissipation through the frictional damping is enough to stabilize the system exponentially.
\end{abstract}

Mathematics subject classification (2020): 26D10, 35L20, 74H55, 93D15.

Keywords and phrases: Laminated beams, frictional damping, distributed delay, exponential stability.

\section{REFERENCES}

[1] C. Abdallah, P. Dorato, J. Benitez-Read and R. Byrne, Delayed positive feedback can stabilize oscillatory system, ACC. IEEE., (1993), 3106-3107.

[2] M. S. Alves And R. N. Monteiro, Exponential stability of laminated Timoshenko beams with boundary/internal controls, J. Math. Anal. Appl., 482, 1 (2020), 123516.

[3] T. A. Apalara, Exponential Stability of Laminated Beams with Interfacial Slip, Mech. Solids, 56, 1 (2021), 131-137.

[4] T. A. Apalara, Well-posedness and exponential stability for a linear damped Timoshenko system with second sound and internal distributed delay, Electron. J. Differ. Equ., 2014, 254 (2014), 1-15.

[5] T. A. Apalara, Uniform decay in weakly dissipative Timoshenko system with internal distributed delay feedbacks, Acta Math. Sci. Ser. B (Engl. Ed.), 36, 3 (2016), 815-830.

[6] T. A. Apalara, On the Stability of a Thermoelastic Laminated Beam, Acta Math. Sci. Ser. B (Engl. Ed.), 39, 6 (2019), 1517-1524.

[7] T. A. Apalara, C. A. Raposo And C. A. S. Nonato, Exponential stability for laminated beams with a frictional damping, Arch. Math. (Basel), 114, 4 (2020), 471-480.

[8] T. A. Apalara, A. M. Nass and H. Al Sulaimani, On a Laminated Timoshenko Beam with Nonlinear Structural Damping, Math. Comput. Appl., 25, 2 (2020), 35.

[9] X. G. CAO, D. Y. LIU AND G. Q. XU, Easy test for stability of laminated beams with structural damping and boundary feedback controls, J. Dyn. Control Syst., 13, 3 (2007), 313-336.

[10] Z. Chen, W. LiU And D. Chen, General Decay Rates for a Laminated Beam with Memory, Taiwanese J. Math., 23, 5 (2019), 1227-1252.

[11] A. Choucha, D. Ouchenane And S. Boulaaras, Well posedness and stability result for a thermoelastic laminated Timoshenko beam with distributed delay term, Math. Methods Appl. Sci., 43, 17 (2020), 9983-10004.

[12] B. FENG, Well-posedness and exponential decay for laminated Timoshenko beams with time delays and boundary feedbacks, Math. Methods Appl. Sci., 41, 3 (2018), 1162-1174.

[13] B. Feng, T. F. Ma And R. N. Monteiro, Dynamics of laminated Timoshenko beams, J. Dyn. Differ. Equ. 30, 4 (2018), 1489-1507.

[14] B. Feng, On a Thermoelastic Laminated Timoshenko Beam: Well Posedness and Stability, Complexity, 2020, (2020) Article ID 5139419.

[15] B. Feng And A. Soufyane, Memory-type boundary control of a laminated Timoshenko beam, Math. Mech, Solids, 25, 8 (2020), 1568-1588. 
[16] A. Guesmia, Some well-posedness and general stability results in Timoshenko systems with infinite memory and distributed time delay, J. Math. Phys., 55, 8 (2014), 081503.

[17] A. Guesmia AND N. E. TATAR, Some well-posedness and stability results for abstract hyperbolic equations with infinite memory and distributed time delay, Commun. Pure Appl. Anal., 14, 2 (2015), 457-491.

[18] S. W. HANSEN AND R. D. SPIES, Structural damping in laminated beams due to interfacial slip, J. Sound Vibration, 204, 2, (1997), 183-202.

[19] W. LiU, X. Kong AND G. LI, Asymptotic stability for a laminated beam with structural damping and infinite memory, Math. Mech. Solids, 25, 10 (2020), 1979-2004.

[20] W. LiU AND W. ZHAO, Stabilization of a thermoelastic laminated beam with past history, Appl. Math. Optim., 80, 1 (2019), 103-133.

[21] W. LiU, Y. LUAN, Y. LIU AND G. LI, Well-posedness and asymptotic stability to a laminated beam in thermoelasticity of type III, Math. Methods Appl. Sci., 43, 6 (2020), 3148-3166.

[22] A. Lo AND N. E. TATAR, Stabilization of laminated beams with interfacial slip, Electr. J. Differ. Equ., 2015, 129 (2015), 1-14.

[23] A. Lo AND N. E. TATAR, Uniform Stability of a Laminated Beam with Structural Memory, Qual. Theory Dyn. Syst., 15, 2 (2015), 517-540.

[24] K. Mpungu, T. A. Apalara, And M. Muminov, On the Stabilization of Laminated Beams with Delay, Appl. Math., (2021), Online first publication, doi:10.21136/AM.2021.0056-20.

[25] M. I. Mustafa, Laminated Timoshenko beams with viscoelastic damping, J. Math. Anal. Appl., 466, 1 (2018), 619-641.

[26] M. I. Mustafa, Boundary control of laminated beams with interfacial slip, J. Math. Phys., 59, 5 (2018), 051508.

[27] M. I. Mustafa And M. KAFInI, Exponential decay in thermoelastic systems with internal distributed delay, Palest. J. Math., 2, 2 (2013), 287-299.

[28] M. I. MUSTAFA, A uniform stability result for thermoelasticity of type III with boundary distributed delay, J. Math. Anal. Appl., 415, 1 (2014), 148-158.

[29] S. NiCAISE AND C. PignOTTI, Stability and instability results of the wave equation with a delay term in the boundary or internal feedbacks, SIAM J. Control Optim., 45, 5 (2006), 1561-1585.

[30] S. Nicaise And C. PignotTi, Stabilization of the wave equation with boundary or internal distributed delay, Diff. Int. Eqs., 21, 9-10 (2008), 935-958.

[31] C. PignotTi, A note on stabilization of locally damped wave equations with time delay, Syst. Control Lett.61, 1 (2012), 92-97.

[32] C. A. RAPOSO, Exponential stability for a structure with interfacial slip and frictional damping, Appl. Math Lett., 53, (2016), 85-91.

[33] L. Seghour, N. E. TATAR AND A. Berkani, Stability of a thermoelastic laminated system subject to a neutral delay, Math. Methods Appl. Sci., 43, 1 (2020), 281-304.

[34] H. SUh AND Z. BIEN, Use of time-delay actions in the controller design, IEEE Trans. Automat. Contr., 25, 3 (1980), 600-603.

[35] N. E. TATAR, Stabilization of a laminated beam with interfacial slip by boundary controls, Bound. Value Probl., 2015, (2015), 169.

[36] J. M. WANG, G. Q. XU AND S. P. YUnG, Exponential stabilization of laminated beams with structural damping and boundary feedback controls, SIAM J. Control Optim., 44, 5 (2005), 1575-1597. 